pm were collected. The body temperature data after regular bath were collected in the time of $0600 \mathrm{pm}$. The paired ttest was used to compare the difference between body temperature means before and after daytime bath and ANOVA was used to compare the difference between body temperature means after daytime bath and regular bath.

Results There were 93 conscripts participating in this study with response rate of $100 \%$. The results of the analyses showed that the body temperature after daytime bath is lower than before bath in statistically significant $(\mathrm{p}<0.05)$. But, the difference of body temperature between daytime bath and regular bath is not statistically significant. $(p>0.05)$.

Discussion Both regular and daytime bath showed effectiveness in decreasing body temperature. Therefore, daytime bath can be used as additional method to reduce body temperature in the daytime period to prevent heat injury.

\section{OCCUPATIONAL HEAT EXPOSURE OF TRAFFIC POLICE WORKERS IN AHMEDABAD, INDIA}

${ }^{1}$ Shyam Pingle* , ${ }^{2}$ Amee Raval, ${ }^{1}$ Priya Dutta, ${ }^{1}$ Abhiyant Tiwari, ${ }^{1}$ PS Ganguly, ${ }^{1}$ LM Sathish, ${ }^{1}$ Dileep Mavalankar, ${ }^{3}$ Jeremy Hess, ${ }^{4}$ Anjali Jaiswal. ${ }^{1}$ Indian Institute of Public Health Gandhinagar, Gandhinagar, India; '2University of California, Berkeley; ${ }^{3}$ University of Washington, Seattle, USA; ${ }^{4}$ Natural Resources Defense Council, San Francisco, USA

\subsection{6/oemed-2018-ICOHabstracts. 1425}

Introduction Climate change is causing rising levels of extreme heat. Traffic police workers form a vulnerable group exposed to high atmospheric temperature in temperate countries like India. A heat exposure assessment among traffic police has not been previously undertaken in an Indian city. Therefore, a pilot study was conducted with plans for an exhaustive study in future.

Methods This study was conducted over a six-week period during June and July 2015 at four Traffic junctions in Ahmedabad on 16 traffic policemen. Personal ambient temperature was measured by data loggers, Wet-bulb-globe temperature and ambient temperature measurements were also recorded. Ahmedabad city Temperature Measurement data corresponding to the monitoring period was collected from Indian Meteorological Department. A questionnaire was administered to all participants to collect demographic data and history of heat related symptoms. Follow up was done to capture prevalence of heat-related symptoms over the study period.

Result The average age of study participants was 35.1 years. $94 \%$ of participants reported that the summer is the most uncomfortable season to work. The dry bulb and globe bulb temperature ranged from $31.6^{\circ} \mathrm{C} \pm 0.3^{\circ} \mathrm{C}$ to $36.8^{\circ} \mathrm{C} \pm 1.6^{\circ} \mathrm{C}$ and $34.6^{\circ} \mathrm{C} \pm 1.0^{\circ} \mathrm{C}$ to $49.1^{\circ} \mathrm{C} \pm 3.0^{\circ} \mathrm{C}$ respectively. Area WBGT heat stress measurements for all four traffic junctions ranged from $28.2^{\circ} \mathrm{C}$ to $36.1^{\circ} \mathrm{C}$ during the study period. Participants experienced high heat exposures during the study period. Daily WBGT measurements exceeded the maximum recommended exposure at each of the four outdoor worksites.

Discussion This study offers one of the first data sets on ambient heat exposure of traffic police workers in an urban context. The occupational heat stress exposure resulting from outdoor work in traffic junctions is likely to have implications for health. Further, it is observed that the exposures of people who work near roadways is not well characterised by conventional temperature monitoring stations. Various strategies are recommended to protect traffic police from heat exposures.

\section{THE EFFECTS OF AMBIENT TEMPERATURE ON WORK- RELATED INJURIES IN ADELAIDE, AUSTRALIA- WORKERS' COMPENSATION CLAIMS INCREASE WITH HIGH TEMPERATURES}

${ }^{1}$ Blesson M Varghese*, ${ }^{2}$ Adrian G Barnett, ${ }^{1}$ Alana L Hansen, ${ }^{1}$ Peng Bi, 'Dino L Pisaniello. ${ }^{1}$ School of Public Health, The University of Adelaide, Australia; ${ }^{2}$ School of Public Health and Institute of Health and Biomedical Innovation, Queensland University of Technology, Brisbane, Australia

\subsection{6/oemed-2018-ICOHabstracts. 1426}

Introduction Ambient thermal stress may directly, or indirectly, increase the risk of work-related injuries, particular for outdoor workers. However, little is known about the overall injury burden contributed by ambient temperatures (both high and low). The objectives of this study were to examine the relationship between ambient temperatures and work-related injuries and illnesses as well as quantify the associated burden at both ends of the temperature spectrum.

Methods Daily numbers of worker's compensation claims for injuries and illnesses in the Adelaide metropolitan area from 2003-2013 $(n=224,631)$ were provided by the jurisdictional regulator. Daily weather data were obtained from the Australian Bureau of Meteorology. We used a time-stratified casecrossover regression model combined with distributed lag nonlinear to quantify the cumulative effect of temperatures over the previous 7 days. The burden of low and high temperatures was computed and further separated into effects related to mild and extreme temperature ranges. Analyses were stratified by worker, work environment and injury characteristics.

Results As the daily maximum temperatures rose above $25^{\circ} \mathrm{C}$, the risk of work-related injuries and illnesses also increased. Compared with the optimum temperature (minimum claim likelihood), extreme high temperatures (99th percentile) were associated with a $30 \%(95 \% \mathrm{CI}$ : $18 \%$ to $44 \%)$ increase in overall claims whereas no statistically significant association was observed with cold temperatures (1 st percentile). Longer delayed effects were seen for cold temperatures, whereas acute effects were seen in hot conditions. Notably, moderate temperature ranges were associated with greater injury burden than extreme temperatures.

Conclusion The results suggest a J-shaped relationship between temperature and injury claims with the highest extreme temperatures having the greatest risk but the more common hot days having the greatest burden. Companies and supervisors should be aware that heat-related injuries can arise even in moderately hot conditions. Injury prevention interventions should therefore consider ambient temperature risks more broadly.

\section{HOT ENVIRONMENT: EFFECTS OF A POWER ASSISTED FILTERING DEVICE INCORPORATING A FULL FACE MASK ON NEWTON MANIKIN THERMOPHYSIOLOGICAL RESPONSE}

${ }^{1}$ Simona Del Ferraro, ${ }^{2}$ Francesca Tombolini, ${ }^{3}$ Carmela Plebani, ${ }^{4}$ Sergio Iavicoli, ${ }^{4}$ Marta Petyx*, ${ }^{1}$ Vincenzo Molinaro. ${ }^{1}$ INAIL DiMEILA, Laboratory of Ergonomics and Physiology - Monte Porzio Catone - Italy; ${ }^{2}$ INAIL DiMEILA, Laboratory of Carginogenic and Mutagenic Agents Risks - Monte Porzio Catone - Italy; ${ }^{3}$ INAIL DiMEILA, Laboratory of Chemical Agent Risk - Monte Porzio Catone - Italy; ${ }^{4}$ INAIL DiMEILA, Monte Porzio Catone - Italy

10.1136/oemed-2018-ICOHabstracts. 1427 